\title{
BIOS approach tested for controlling walnut pests in San loaguin Valley
}

\author{
Joseph A. Grant \\ Walt Bentley \\ Carolyn Pickel \\ Jeannine Groh-Lowrimore
}

As concerns increase over changes in pesticide regulations, farmworker safety, surface and groundwater contamination and escalating costs and uncertainties associated with chemical controls, walnut growers need effective and cost-efficient ways to produce walnuts with minimal use of pesticides. This study compared the effectiveness of Biologically Integrated Orchard Systems (BIOS) with conventionally managed walnut orchards in the northern San Joaquin Valley from 1999 to 2001. We found no significant differences between BIOS and conventional blocks in nut quality or yields. Codling moth was effectively controlled by pheromone disruption and alternative pest-control methods. Mating disruption, by itself, appears to provide good control of codling moth in many orchards. However, it is still more expensive for growers than conventional pest-control methods.

7 he Community Alliance with Fam1 ily Farmers (CAFF), through its innovative Biologically Integrated Orchard Systems (BIOS) project in Yolo and Solano counties, demonstrated from 1996 to 1999 that it is possible to reduce pesticide use and still produce good yields of high-quality walnuts with low levels of pest damage (CAFF 1999). BIOS emphasizes intensive monitoring, biological control and beneficial insect habitat enhancement to control pests; cover crops, animal manures and composts to build soil; and measured use of fertilizers based on nutrient budgeting and leaf tissue anal-

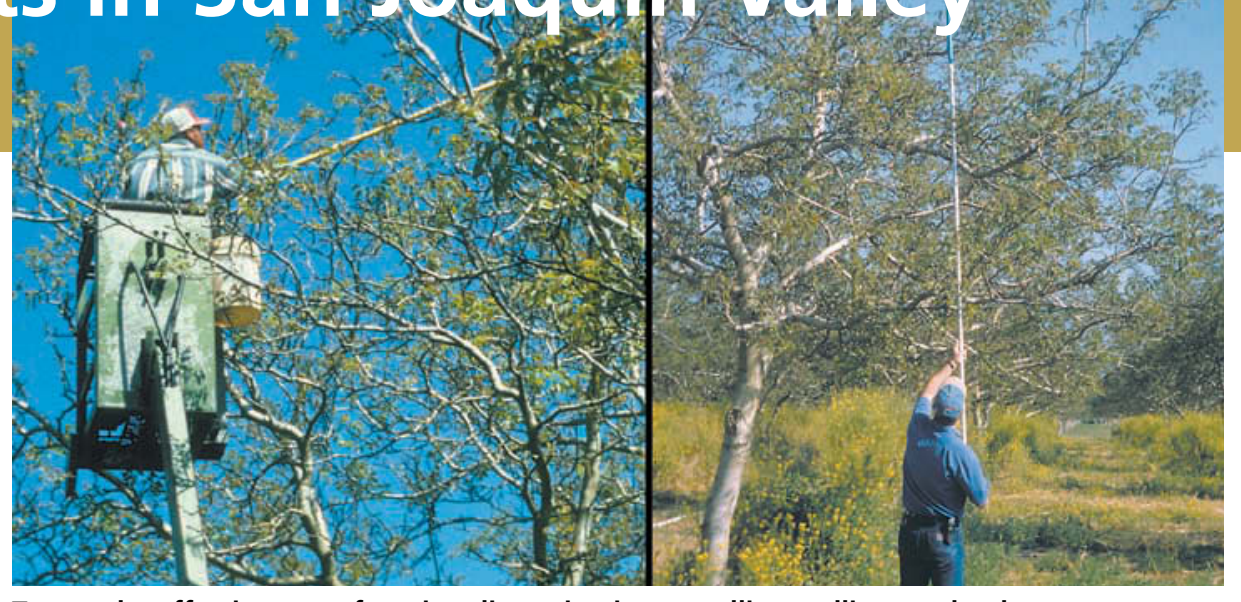

To test the effectiveness of mating disruption in controlling codling moth, pheromone dispensers were applied to walnut trees in the northern San Joaquin Valley. The dispensers must be hung by hand either from a pruning tower, left, or the ground, right.

ysis to optimize fertilizer use (Swezey and Broome 2000).

From 1999 to 2001, we conducted a project aimed at adapting the BIOS model to fit the biological, economic and infrastructure conditions of the walnut farming industry in the northern San Joaquin Valley. Our primary focus was pest management, including control of three key walnut pests:

codling moth, aphids and mites.

\section{BIOS, conventional blocks compared}

Ten growers participated in the project in 1999, and 12 in 2000 and 2001.

Each grower designated a block of mature walnuts for BIOS implementation. BIOS blocks were chosen based on variety, previous crop and pest history and the growers' preferences. These blocks included a variety of walnut cultivars and orchard designs in eastern San Joaquin and northern Stanislaus counties (table 1). Nine of the 12 growers in 2000 and 2001 designated an adjacent portion of the same block or a nearby block - of the same variety and similar size, age and cultural characteristics - to serve as a conventionally managed comparison block. At our request, most of the growers retained a pest control advisor (PCA) experienced in BIOS or other alternative farming methods to provide management advice in BIOS blocks. Independent consultants or PCAs from agricultural supply dealers provided consulting in conventional blocks.

A customized plan for managing codling moth and other pests was developed for each BIOS block by a team

\begin{tabular}{|c|c|c|c|c|c|}
\hline \multirow[b]{2}{*}{ Site } & \multirow[b]{2}{*}{ Variety } & \multirow{2}{*}{$\begin{array}{l}\text { Varietal codling } \\
\text { moth susceptibility }\end{array}$} & \multicolumn{2}{|c|}{ Block size (acres) } & \multirow{2}{*}{$\begin{array}{l}\text { BIOS/conv. } \\
\text { configuration }\end{array}$} \\
\hline & & & BIOS & Conv. & \\
\hline A & Vina & Moderate & 16 & 47 & Single block, split \\
\hline B & Chandler & Low & 20 & 20 & Single block, split \\
\hline C & Vina & Moderate & 10 & 10 & Single block, split \\
\hline D & Serr \& Sunland & High & 20 & 20 & Single block, split \\
\hline $\mathbf{E}$ & Hartley & Low & 20 & 54 & Adjacent blocks \\
\hline $\mathbf{F}$ & Vina & Moderate & 13 & 9 & Adjacent blocks (1999 only)* \\
\hline G & Vina & Moderate & 10 & 10 & $\begin{array}{l}\text { Separated by small } \\
\text { 'Waterloo' block }\end{array}$ \\
\hline $\mathbf{H}$ & Vina & Moderate & 11 & None & N/A \\
\hline I & Vina \& Serr & Moderate/high & 23 & None & N/A \\
\hline J & Hartley & Low & 20 & None & N/A \\
\hline $\mathbf{K}$ & Serr & High & 15 & 39 & Single block, split \\
\hline $\mathbf{L}$ & Hartley & Low & 10 & 10 & Adjacent blocks \\
\hline
\end{tabular}


of technical experts, consisting of the local UC Cooperative Extension farm advisor, two UC integrated pest management advisors, two walnut growers with BIOS or organic walnut farming experience, four individuals with BIOS-related expertise (cover crops, soil building, pest management), two PCAs and a representative of a major California walnut processor. Growers agreed to follow the management plan as closely as possible in BIOS blocks. Growers and their consultants and PCAs determined pest management practices in the conventionally managed comparison blocks.

We developed a comprehensive monitoring program, which included weekly monitoring of BIOS and conventionally managed blocks by a project field scout from April through October for key pests, using established sampling methods (UC IPM 1987, 2000). Monitoring results were summarized and delivered to growers and their PCAs each week.

We used data from growers' harvest delivery and grading reports to compare yield and quality in BIOS and conventionally managed blocks. We also evaluated nut quality using harvest samples we collected when trees were shaken for commercial harvest. We inspected 60 randomly selected nuts collected from each of 10 preselected trees per block for quality defects and pest damage (total of 600 nuts per block). These trees were located at regular intervals along a middle row in each block. We also obtained yield information from questionnaires completed by growers each year.

\section{Managing codling moth}

Codling moth is the key insect pest of walnuts, and it was the major focus of our efforts. Codling moth has three generations per year in the northern San Joaquin Valley. Feeding by first-generation larvae causes damaged nuts to drop from trees. Second and third generation larvae bore into nuts and damage the kernel. Most of these nuts remain on the tree until harvest but are unmarketable. In BIOS blocks, we proposed a careful combination of intensive monitoring of pests and beneficial insects with thoughtful deployment of one or more alternatives to conventional insecticides.
These included pheromone mating disruption, releases of the codling moth parasitoid Trichogramma platneri, and insecticides that would not disrupt biological control of other pests.

Pheromone mating disruption. We tested several hand-applied pheromone mating-disruption products in BIOS blocks. Two companies currently produce hand-applied pheromone dispensers for use in walnuts. Each manufacturer has developed small, specially designed plastic dispensers containing small amounts of codling moth pheromone. Most growers used motorized pruning towers to reach the upper parts of tree canopies, and attached the dispensers - directly by hand or with the aid of a specially configured pole - to branches near the tops of trees.

We used Isomate C+, a currently available mating-disruption product (Pacific Biocontrol), in one BIOS block (C) in 1999; five blocks (C, D, F, I and $\mathrm{K})$ in 2000; and four blocks (C, E, F and $\mathrm{H})$ in 2001. A single application at a rate of 400 dispensers per acre was made at biofix (the start of egg laying by the first flight) of the overwintered generation in each block. Isomate CTT (Pacific Biocontrol), another hand-

applied product with the same pheromone blend as the $\mathrm{C}+$ formulation but twice as much pheromone per dispenser, was used in two BIOS blocks ( $\mathrm{K}$ and L) in 2001. This product was applied at a rate of 200 dispensers per acre at biofix, affording some savings in application cost over the $C+$ product.

Three growers (A, E and J) used CheckMate CM-XL1000 (Suterra), another commercially available matingdisruption product, in their BIOS blocks in 2000 at a rate of 225 dispensers per acre, applied once per season at biofix.

A recently developed experimental wax emulsion containing codling moth pheromone (Atterholt et al. 1999; Grant et al. 2001) was made available to our project by the manufacturer (Gowan). We used the product in four BIOS blocks (B, E, F and G) in 1999 and three (B, H and L) in 2000. The pheromone emulsion was applied using a pressurized handgun applicator that projected a precisely metered stream of emulsion onto branches or leaves near the tops of trees. The application rate and concentration were designed to provide

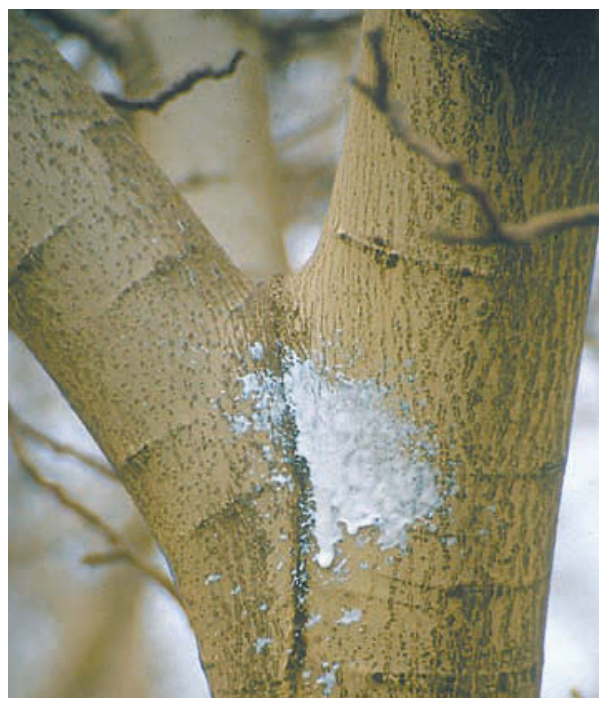

A variety of pheromone mating-disruption products were tested in BIOS and conventional orchards, including a recently developed wax emulsion applied using a pressurized handgun that projects the emulsion near the tops of trees.

40 grams of codling moth pheromone per acre per application in 2000. A first application was made at biofix in early April, and subsequent applications at 4- to 6-week intervals.

Two manufacturers produce bulk pheromone dispensers, known generically as puffers, for disrupting codling moth mating. Puffers consist of a pressurized disposable can filled with pheromone and propellant, fitted with a valve and nozzle assembly and a battery-operated controller. The controller is programmed to release precise doses of pheromone at timed intervals. The dispensers, hung near the tops of trees at rates of one per 1 to 2 acres, offer considerable potential savings in application labor over dispensers such as Isomate $\mathrm{C}+$ and CTT. We deployed experimental puffers manufactured by Pure Green Solutions at a rate of one per acre in three BIOS blocks (A, D and G) in 2001.

Two manufacturers have developed sprayable pheromone formulations. In these products, codling moth pheromone is contained in very small (10- to 200-micron diameter) spherical polymer capsules suspended in a liquid carrier. When sprayed in the orchard, these capsules adhere to leaves and other tree surfaces and slowly release pheromones into the air. An advantage 
TABLE 3. Total seasonal average $1 X$ pheromone trap captures in BIOS (after deployment of mating disruption*) and conventional blocks

\begin{tabular}{llrrr}
\hline \hline & & 1999 & 2000 & 2001 \\
\hline A & BIOS & 490 & 67 & 4 \\
& Conv. & 525 & 562 & 492 \\
\hline B & BIOS & 0 & 1 & 0 \\
& Conv. & 80 & 75 & 200 \\
\hline C & BIOS & 4 & 7 & 10 \\
& Conv. & 688 & 677 & 295 \\
\hline D & BIOS & 245 & 0 & $<1$ \\
& Conv. & 240 & 332 & 208 \\
\hline E & BIOS & 14 & 20 & $<1$ \\
& Conv. & 331 & 326 & 85 \\
\hline F & BIOS & 31 & 5 & $<1$ \\
& Conv. & 993 & N/A & N/A \\
\hline G & BIOS & 2 & 50 & $<1$ \\
& Conv. & 196 & 98 & 32 \\
\hline H & BIOS & 175 & 24 & 1 \\
\hline I & BIOS & 764 & 16 & 2 \\
\hline J & BIOS & 1224 & 695 & 168 \\
\hline K & BIOS & N/A & 4 & $<1$ \\
& Conv. & N/A & 382 & 250 \\
\hline L & BIOS & N/A & 12 & $<1$ \\
& Conv. & N/A & 276 & 101 \\
\hline Usef & Mating disruption & is & & \\
\hline
\end{tabular}

* Use of mating disruption is indicated by colored numerals.

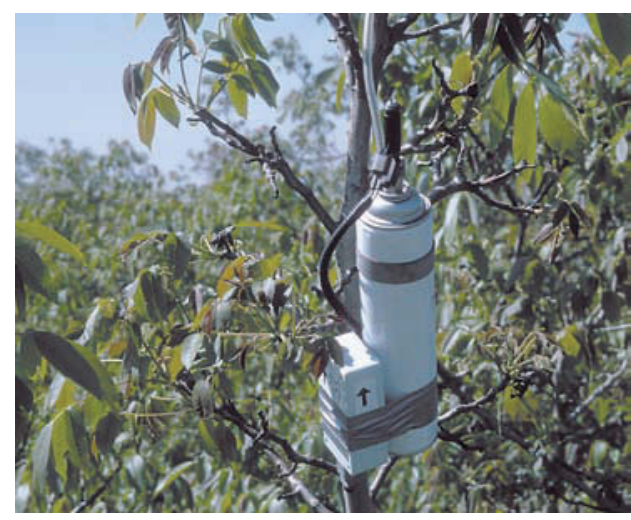

Pheromones can be applied in aerosol form such as this experimental microsprayer, or "puffer," which releases precise doses at timed intervals.

TABLE 4. Average number codling-moth-damaged dropped nuts under trees during first generation, and percent nuts with codling moth damage during first and second canopy damage assessments, in paired BIOS and conventional blocks*

\begin{tabular}{cccccc}
\hline \hline Year & $\begin{array}{c}\text { No. } \\
\text { sites }\end{array}$ & Block & $\begin{array}{c}\text { No. drop } \\
\text { nuts/tree }\end{array}$ & $\begin{array}{c}\% \\
\text { damage, } \\
\text { June }\end{array}$ & $\begin{array}{c}\% \\
\text { damage, } \\
\text { August }\end{array}$ \\
\hline 1999 & 7 & BIOS & 0.2 & 0.14 & 0.06 \\
& & Conv. & 0.5 & 0.03 & 0.69 \\
& & & ns & ns & ns \\
\hline 2000 & \multirow{2}{*}{8} & BIOS & 1.5 & 0.43 & 0.66 \\
& & Conv. & 1.7 & 0.23 & 0.48 \\
& & & ns & ns & ns \\
\hline 2001 & 8 & BIOS & 3.9 & 0.21 & 0.45 \\
& & Conv. & 4.7 & 0.06 & 0.48 \\
& & & ns & s & ns \\
\hline
\end{tabular}

$\mathrm{ns}=$ Difference between $\mathrm{BIOS}$ and conventional blocks not significant.

$\mathrm{s}=$ Significant at $P \leq 0.05$. nondisruptive to beneficial insects in the orchard. Phosmet was recommended as an alternative to tebufen-ozide in BIOS blocks with severe codling moth pressure or where first-generation treatment was necessary. The growers and their PCAs made decisions to treat BIOS blocks for other pests - and conventional blocks for all pests - based on their individual experiences and objectives.

Growers treated conventional blocks with standard pesticides at registered rates, including chlorpyrifos (Lorsban), esfenvalerate (Asana), phosmet (Imidan) or methyl parathion (Penncap-M) for codling moth; propargite (Omite) or clofentezine (Apollo) for mites; and chlorpyrifos or naled (Dibrom) for aphids. Though growers were informed of and asked to adhere to recognized treatment thresholds for particular pests, they were generally allowed to treat BIOS and conventional blocks as they deemed necessary to ensure acceptable yields and quality. Growers reported pesticide applications for codling moth and other pests in year-end questionnaires.

\section{BIOS effectiveness evaluated}

Yields and quality. Nut yields were similar in BIOS and conventional blocks in all three years of the project (table 2). Nut quality, as measured by processor grading evaluations, was also comparable. Kernel damage by insects was never great enough to trigger processor payment penalties, though mold damage resulted in off-grade penalties in both BIOS and conventional blocks in some years. Nuts sampled at harvest showed no significant differences between BIOS and conventional blocks in nut damage or kernel quality, except for a slight increase in darkened kernels in one year.

In general, our harvest samples showed more damage than processors' grading reports, especially non-insectrelated defects such as moldy, shriveled and darkened kernels. This occurred because some damaged nuts (e.g., shriveled and oilless) are removed by harvest and hulling equipment prior to processor delivery and because our harvest evaluations included defects such as dark kernels that processors do not necessarily consider rejectable. As such, our harvest samples were a more sensitive and comprehensive indicator of quality differences than processor grading results, though the latter determine the actual price paid for nuts by the processor.

Codling moth. Codling moth pressure, as measured by pheromone trap captures, varied greatly among the orchards (table 3). Trap catches were generally lower in pheromone-matingdisruption BIOS blocks, though the various technologies differed in longevity of suppression and in the amount of occasional captures of male moths.

Results of first-generation droppednut counts showed low levels of earlyseason codling moth damage in most blocks (table 4). There were no significant differences between BIOS and conventional blocks in the number of dropped nuts. The numbers of codling moth-damaged nuts in midseason canopy damage assessments were acceptably low at all sites in all years. Except for the first canopy damage assessment in 2001, when BIOS blocks had slightly greater average damage than conventional blocks, there were no significant differences between BIOS and conventional blocks.

A single application of Isomate C+ or CTT suppressed trap captures for the entire season at all sites where these products were used (table 5). Nut damage in these sites, as measured by canopy damage assessments and harvest evaluations, was also low and comparable to that in conventional blocks.

A single application of CheckMate CM-XL1000 suppressed trap captures at the three sites where it was used in 2000 until mid-July, when a resumption of low-level trap captures indicated that the product was depleted of pheromone. The average weekly trap capture in these blocks was only 0.3 moths per trap before July 16; it was 5.3 moths per trap thereafter. This late-season activity was great enough to warrant chemical treatment at one of the sites. Two of the three blocks where this product was used had the greatest codling moth damage at harvest $(4.3 \%$ and $2.2 \%$ ) of all the mating-disrupted blocks.

The pheromone wax emulsion suppressed pheromone trap captures for at least 30 days after application (Grant et al. 2001). Under the relatively low codling-moth pressure conditions that 
TABLE 5. Performance of alternative approaches used to control codling moth in paired BIOS and conventional blocks*

\begin{tabular}{|c|c|c|c|c|c|c|}
\hline $\begin{array}{l}\text { Codling moth } \\
\text { management } \\
\text { practice }\end{array}$ & $\begin{array}{c}\text { Year(s): } \\
\text { sites used }\end{array}$ & $\begin{array}{l}\text { Avg. seasonal } \\
\text { trap capture } \\
\text { (moths/trap) }\end{array}$ & $\begin{array}{c}\text { No. } \\
\text { dropped nuts } \\
\text { per tree }\end{array}$ & $\begin{array}{c}\text { June } \\
\text { assessment, } \\
\% \text { damage }\end{array}$ & $\begin{array}{c}\text { August } \\
\text { assessment, } \\
\% \text { damage }\end{array}$ & $\begin{array}{c}\text { Harvest } \\
\text { damage, \% }\end{array}$ \\
\hline Isomate $C_{+}$ & 1999: C & 4 & 1.1 & 0.3 & 0.6 & 0.9 \\
\hline \multirow[t]{2}{*}{ Conventional } & 2000: C, D, K & 409 & 2.1 & 0.2 & 0.8 & 1.1 \\
\hline & 2001: C, E & ss & ns & ns & ns & ns \\
\hline Isomate CTT2001: K, L & $<1$ & 1.2 & 0.5 & 0.5 & 0.8 & \\
\hline \multirow[t]{2}{*}{ Conventional } & & 176 & 2.8 & 0.0 & 0.0 & 0.3 \\
\hline & & ns & ns & ns & ns & ns \\
\hline CheckMate CM-XL1000 & 2000: A, E, G & 46 & 1.0 & 0.5 & 0.8 & 2.4 \\
\hline \multirow[t]{2}{*}{ Conventional } & & 329 & 1.2 & 0.1 & 0.2 & 0.7 \\
\hline & & ns & ns & ns & ns & ns \\
\hline Pheromone emulsion & 1999: B, E, G & 6 & 1.7 & 0.2 & 0.1 & 0.2 \\
\hline \multirow[t]{2}{*}{ Conventional } & 2000: B, L & 192 & 1.2 & 0.1 & 0.04 & 0.2 \\
\hline & & Ss & ns & ns & ns & ns \\
\hline Tebufenozide $+T$. platneri & 1999: A, D & 368 & 0.1 & 0.4 & 0.2 & 0.7 \\
\hline \multirow[t]{2}{*}{ Conventional } & & 383 & 0.1 & 0.0 & 1.5 & 0.5 \\
\hline & & ns & ns & ns & ns & ns \\
\hline
\end{tabular}

* $\mathrm{ns}=$ Difference between BIOS and conventional blocks not significant.

ss $=$ Significant at $P \leq 0.01$

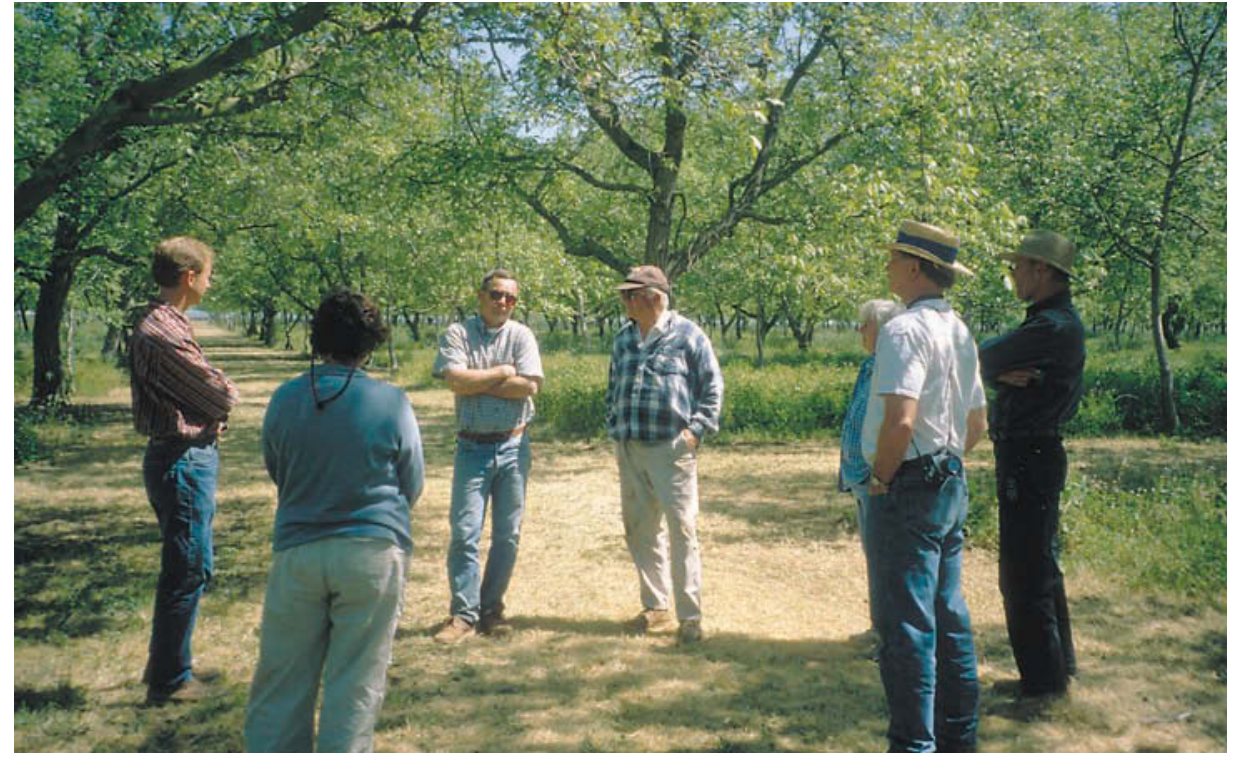

The BIOS implementation team, consisting of growers, UC advisors and technical experts, visited with growers at the beginning of the project to suggest strategies for reducing pesticide use.

prevailed in orchards where this material was used in 1999, the longevity of the emulsion was such that two applications were sufficient for the season. Three applications were needed in 2000. This material provided good control of nut damage during the season and at harvest.

Early in the 2001 season, we found that some puffers deployed at BIOS blocks $A, B$ and $G$ were malfunctioning and releasing variable amounts of pheromone. Because of this, the units were removed from BIOS blocks $\mathrm{A}$ and $\mathrm{G}$ in early June and Isomate $\mathrm{C}+$ dispensers were hung to disrupt mating for the balance of the season. We used properly operating puffers to replace malfunctioning ones at BIOS block D, where they provided good suppression of trap captures (total seasonal capture of 0.3 moths per trap) and nut damage (0.3\% at harvest).

The Suterra sprayable formulation used in BIOS blocks B and I in 2001 provided good suppression of pheromone trap captures throughout the season (total seasonal trap captures were 0 and 2.0 moths per trap, respectively). However, both these sites had relatively high dropped-nut counts (19 and 10 per tree, respectively), and the tall Serr trees at site I had relatively high damage levels in canopy assessments $(1.5 \%$ and $4.2 \%$ in the June and August assessments, respectively) and at harvest (4.5\%).
Orchards treated with a combination of tebufenozide and T. platneri releases had acceptably low levels of nut damage during the season and at harvest.

\section{Good codling moth control}

Our results lead us to the provisional conclusion that mating disruption, by itself, can provide good control of codling moth in many orchards. It is least likely to be successful as a sole treatment in orchards with susceptible varieties, tall canopies and historically large codling moth populations. Ongoing research with sprayable and puffer formulations will address whether this limitation can be overcome using more frequent or higher doses.

Walnut growers and PCAs with conventional orchards currently base their codling moth management decisions on prior damage and in-season assessments of pheromone trap captures and nut damage. Because pheromone trap captures are greatly reduced in matingdisrupted orchards, they are not considered useful for assessing moth activity. Statistical comparisons of trap captures and harvest damage in our project's mating-disruption blocks showed that pheromone trap captures were poor indicators of potential damage within the range of relatively low damage levels observed in the mating-disrupted block (linear regression is significant at $P \leq$ $\left.0.01, r^{2}=0.24\right)$. Work is currently under way to evaluate a new codling moth lure based on a pear fruit volatile that attracts both male and female moths and may allow more accurate tracking 
TABLE 6. Duration and intensity of web-spinning mite infestations and mite predators, in paired BIOS and conventional blocks $(n=23), 1999-2001 *$

\begin{tabular}{|c|c|c|c|c|c|c|}
\hline & \multicolumn{3}{|c|}{ Web-spinning mites } & \multicolumn{3}{|c|}{ Mite predatorst } \\
\hline & $\begin{array}{l}\text { No. weeks } \\
\text { detected }\end{array}$ & $\begin{array}{c}\text { Avg. } \% \\
\text { leaflets } \\
\text { mites }\end{array}$ & $\begin{array}{l}\text { Max. \% } \\
\text { leaflets } \\
\text { w/mites }\end{array}$ & $\begin{array}{l}\text { No. weeks } \\
\text { detected }\end{array}$ & $\begin{array}{c}\text { Avg. } \% \\
\text { leaflets } \\
\text { w/predators }\end{array}$ & $\begin{array}{c}\text { Max. \% } \\
\text { leaflets } \\
\text { w/predators }\end{array}$ \\
\hline BIOS & 6.3 & 14.3 & 29.0 & 8.6 & 14.7 & 37.1 \\
\hline \multirow[t]{2}{*}{ Conv. } & 6.0 & 11.3 & 26.8 & 6.5 & 11.3 & 24.2 \\
\hline & ns & ns & ns & $s$ & $S$ & $S$ \\
\hline
\end{tabular}

* $\mathrm{ns}=$ Difference between $\mathrm{BIOS}$ and conventional blocks not significant

$\mathrm{s}=$ Significant at $P \leq 0.05$

$\dagger$ Includes six-spotted thrips and western orchard predator mites.

of activity in mating-disrupted walnut orchards (Light et al. 2001, 2002).

Although early-season counts of codling-moth-damaged dropped nuts are used as an indicator of damage in conventionally managed orchards, we found no relationship between dropped-nut counts and codling moth damage at harvest in matingdisrupted blocks (linear regression is not significant at $P \leq 0.05$ ). Midseason canopy damage assessments proved a somewhat better predictor of eventual harvest damage in mating-disrupted blocks, though all but $0.5 \%$ and $0.3 \%$ of harvest damage was already present by the time assessments were made at the end of the first and second codling moth flights, respectively. (Linear regression for first canopy assessment is not significant at $P \leq 0.05$; regression is significant for second assessment at

$P \leq 0.001, r^{2}=0.56$.) If codling moth had not been controlled as effectively by mating disruption in these blocks, canopy damage assessments may not have provided adequate advance warning of a codling moth problem.

\section{Pheromone product costs}

Although we demonstrated that many of the pheromone-dispensing technologies can control codling moth effectively in walnuts, they must also be cost-competitive with pesticides for growers to use them. Of the various mating-disruption products we tested, only the hand-applied dispensers were registered for use and commercially available in California. Approximate 2001 retail prices were $\$ 110$ per acre per application for Isomate $\mathrm{C}+$ and $\mathrm{CTT}$ and \$140 for CheckMate CM-XL1000. Application costs were $\$ 50$ to $\$ 90$ for Isomate $\mathrm{C}+, \$ 25$ to $\$ 50$ for Isomate CTT, and \$15 to $\$ 26$ for CheckMate CM-XL1000. Project growers' annual average codling- moth management costs in conventional blocks, as provided by growers in yearend surveys, ranged from $\$ 76$ to $\$ 112$ per acre. Therefore, growers consider hand-applied products prohibitively expensive compared with conventional pesticides. The cost of the pheromone emulsion product could not be estimated because it was experimental and is not currently commercially available. The cost of applying the emulsion averaged $\$ 7$ per acre per application in our tests - around \$14 to \$21 per acre depending on the number of applications needed for

season-long control. If they are shown to be effective in ongoing tests, pheromone puffers (now available for codling moth from Suterra) and sprayable formulations (now available from Suterra and $3 \mathrm{M}$ ) offer the prospect of achieving good control at lower costs than the hand-applied products. Costs per acre for these products are unknown because the amounts of product needed per acre are still under investigation.

\section{Control of mites and aphids}

During the 3 years of the project, web-spinning mite infestations were similar in BIOS and conventional blocks (table 6). Mite predators (six-spotted thrips and western predatory mites), on the other hand, were significantly more abundant in BIOS blocks, though the difference was small. These findings contradict the broadly held assertion that mites can be reduced by eliminating or reducing broad-spectrum insecticides (UC IPM 1987, 2000). In some cases, lateseason changes in mite and predator populations indicated that mites were effectively controlled in BIOS blocks by their natural predators. Overall, however, our results suggest that biological control of two-spotted mites was not strongly enhanced by reducing disruptive insecticide treatments for codling moth, at least not to a degree where the need for miticide applications was reduced. BIOS and conventional blocks needed chemical treatment for mites with roughly equal frequency over the 3-year project.

Averaged over 3 years, the duration and intensity of walnut aphid and walnut aphid parasitoid activity were similar in BIOS and conventional blocks (table 7). Apparently, walnut aphids were controlled as well by parasitoids in BIOS blocks as by late-season insecticide applications in conventional blocks. The dusky-veined aphid was present at some sites and reached greater average infestation levels in BIOS than in conventional blocks. Only one BIOS block $(\mathrm{H})$ was treated each year for this pest.

Natural enemies. Seasonal compilation of general predator observations made by the project field scout showed that lady beetles and syrphid fly larvae - both aphid predators - and lacewings - effective general predators of mites and aphids - were significantly more abundant in BIOS than in conventional blocks (table 8 ).

TABLE 7. Duration and intensity of aphids and their parasites in BIOS and conventional blocks, 1999-2001* +

\begin{tabular}{|c|c|c|c|c|c|c|c|c|c|}
\hline & \multicolumn{3}{|c|}{ Live walnut aphidsł } & \multicolumn{3}{|c|}{ Parasitized walnut aphid mummies } & \multicolumn{3}{|c|}{ Dusky-veined aphids } \\
\hline & $\begin{array}{c}\text { No. } \\
\text { weeks } \\
\text { detected }\end{array}$ & $\begin{array}{c}\text { Avg. no. } \\
\text { leaflet }\end{array}$ & $\begin{array}{l}\text { Max. no. } \\
\text { per leaflet }\end{array}$ & $\begin{array}{c}\text { No. } \\
\text { weeks } \\
\text { detected }\end{array}$ & $\begin{array}{c}\text { Avg. no. } \\
\text { mummies/ } \\
\text { leaflet }\end{array}$ & $\begin{array}{l}\text { Max. no. } \\
\text { mummies/ } \\
\text { leaflet }\end{array}$ & $\begin{array}{c}\text { No. } \\
\text { weeks } \\
\text { detected }\end{array}$ & $\begin{array}{c}\text { Avg. } \% \\
\text { leaflets } \\
\text { with DVA }\end{array}$ & $\begin{array}{l}\text { Max. \% } \\
\text { leaflets } \\
\text { with DVA }\end{array}$ \\
\hline BIOS & 9.6 & 1.0 & 4.2 & 10.8 & 0.8 & 2.2 & 4.9 & 7.1 & 14.5 \\
\hline \multirow[t]{2}{*}{ Conv. } & 8.4 & 1.0 & 3.6 & 9.6 & 0.7 & 1.7 & 2.4 & 2.6 & 10.1 \\
\hline & ns & ns & ns & ns & ns & ns & ns & s & ns \\
\hline
\end{tabular}

* $\mathrm{ns}=$ Difference between $\mathrm{BIOS}$ and conventional blocks not significant.

$S=$ Significant at $P \leq 0.05$.

† Only paired BIOS and conventional sites where walnut aphids $(n=16)$, aphid mummies $(n=16)$ or dusky-veined aphids $(n=8)$ present were used for comparison.

¥ Includes data from 2000 and 2001 only. In 1999, live and parasitized walnut aphids were monitored using presence-absence sampling. 


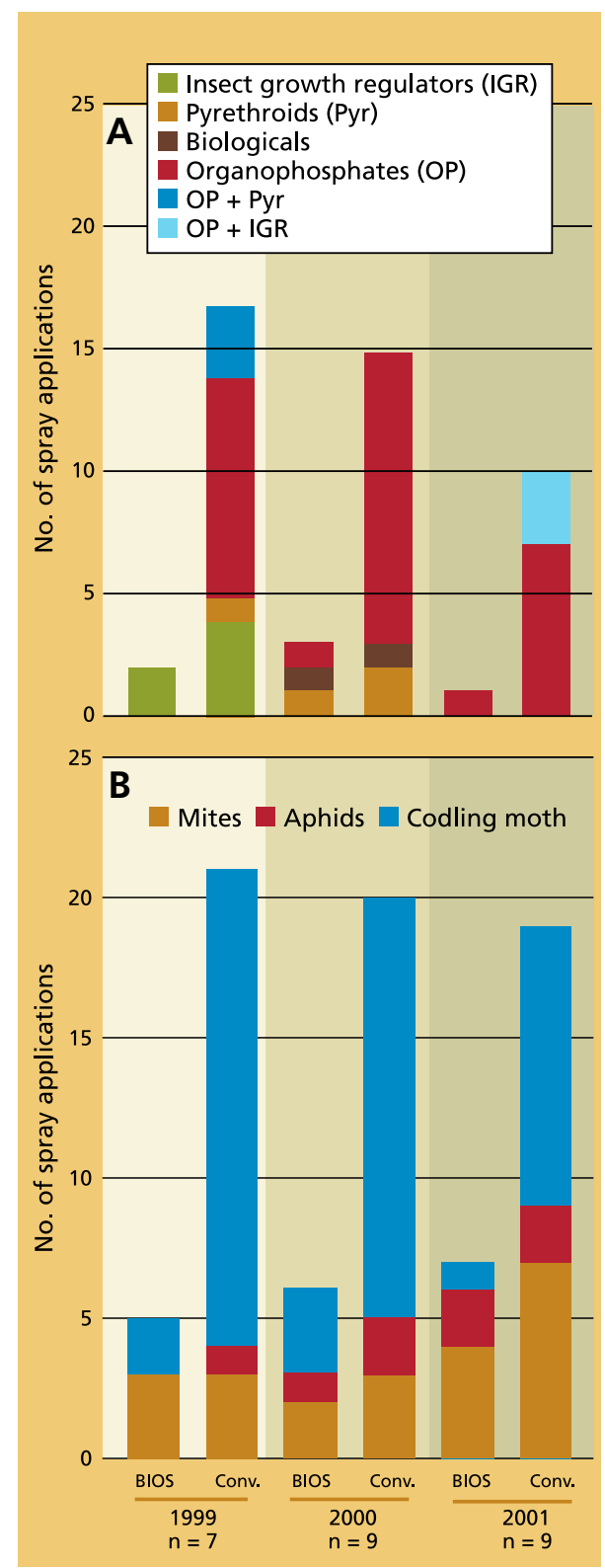

Fig. 1. Number and type of annual pesticide treatments applied for (A) codling moth and (B) all pests in paired BIOS and conventional blocks.

\section{Fewer pesticide applications}

Though the number and type of treatments used each year differed depending on pest abundance, growers' pesticide use records show that our successes in managing key walnut pests in BIOS blocks were achieved while using substantially fewer conventional pesticide applications (fig. 1). The reductions achieved were mainly the result of replacing codling moth sprays with mating disruption and other alternatives. We observed that growers' pesticide use patterns in conventional blocks were similar to other conventional blocks they farmed and to blocks of similar varieties and pest pressure in the area. We do not believe that project growers made more pesticide applications in conventional blocks because of monitoring data made available to them by project personnel.

\section{Effective alternatives}

This project demonstrated that alternative approaches can be used to effectively manage key pests in walnuts. These tactics must be deployed with thoughtful consideration of individual pest and orchard factors, and intensive monitoring is critical for evaluating effectiveness and assessing the need for supplemental pesticide applications. Most of the currently available mating-disruption technologies we tested were effective and helped reduce total pesticide use, but were more costly than conventional pesticide-based programs. Biological control of mites and aphids was enhanced when disruptive insecticides were reduced, but may not be adequate to eliminate pesticide applications for these pests. Ongoing research

TABLE 8. Generalist predators observed in paired BIOS and conventional blocks $(n=23)$ *

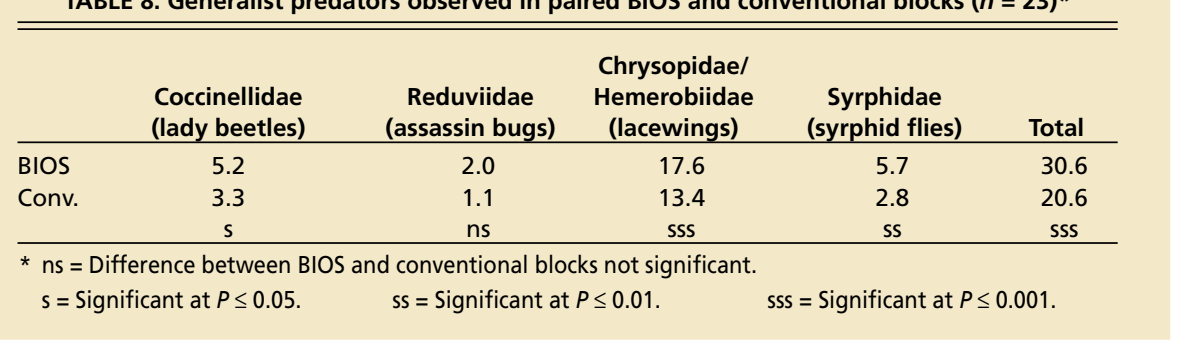

may help address the costs and uncertainties of the BIOS approach, and help identify better methods of assessing pest pressure and potential damage in orchards where they are used.

\section{J.A. Grant is Farm Advisor, UC Cooperative Extension (UCCE), Stockton;}

W. Bentley is IPM Entomologist, UC Kearney Agricultural Center, Parlier;

C. Pickel is Area IPM Advisor, UCCE, Yuba City; and J. Groh-Lowrimore is Staff Research Associate, UCCE, Stockton. The UC Sustainable Agriculture Research and Education Program funded this project. The authors wish to thank project growers for their vision and cooperation and CAFF for inspiring it.

\section{References}

Atterholt CA, Delwiche MJ, Rice RE, Krochta JM. 1999. Controlled release of insect sex pheromones from paraffin wax and emulsions. J Controlled Release 57:233-47.

[CAFF] Community Alliance with Family Farmers. 1999. Biologically Integrated Orchard Systems (BIOS) 1998 Year-End Report. Davis, CA. 18 p.

Grant JA, Giles DK, Brazzle J, Groh J. 2001 New codling moth management tool: Pheromone emulsion shows promise in walnuts. Nut Grower 21(4):8-11.

Light $D$, Knight AL, Henrick CA, et al. 2001. A pear-derived kairomone with pheromonal potency that attracts male and female codling moth, Cydia pomonella (L.). Naturwissenschaften 88:333-8.

Light D, Reynolds K, Grant JA, et al. 2002. Validation and development of a monitoring and management system for codling moth based on a novel female and male attractant kairomone. In: Walnut Research Reports 2001. Sacramento: California Walnut Marketing Board. p 259-304.

Mills NJ, Pickel C, Mansfield S, et al. 2000. Trichogramma inundation: Integrating parasitism into management of codling moth. Cal Ag 54(6):22-5.

Swezey SL, Broome JC. 2000. Growth predicted in biologically integrated and organic farming. Cal Ag 54(4):26-35.

[UC IPM] UC Statewide Integrated Pest Management Program. 1987. Integrated Pest Management for Walnuts, 2nd ed. ANR Pub $3270.96 \mathrm{p}$.

UC IPM. 2000. UC Pest Management Guidelines: Walnuts. ANR Pub 3471.48 p.

Welter SC, Cave F, Singleton M. 2002. Development of alternative pheromone dispensing technologies for management of codling moth. In: Walnut Research Reports 2001. Sacramento: California Walnut Marketing Board. p 225-7. 